\title{
La chispa que enciende nuestra imaginación
}

Santiago Sevilla-Vallejo



Eduardo Martínez Rico, La guerra de las galaxias. El mito renovado, ISBN 9788415238836, Madrid, Alberto Santos Editor, 2017, 286 pp. on la llegada de Star Wars: The Rise of Skywalke [La guerra de las galaxias: El ascenso de Skywalker] a la gran pantalla se cierra una saga de películas que ha ampliado los límites de nuestra imaginación y que ha transformado la cultura a nivel mundial. Todos aquellos que hemos vivido con intensidad las aventuras de los jedi contra los sith podemos ahora reflexionar sobre qué ha significado esta lucha. Eduardo Martínez Rico, quien es doctor en Filología Hispánica, autor de numerosos libros y ensayos, y codirector de Avuelapluma.com, ha reeditado recientemente su libro La guerra de las galaxias. El mito renovado con motivo de los 40 años de la saga. En esta obra, el autor estudia las fuentes de las películas, su sentido antropológico y cultural, y el proceso creativo que les dio lugar. Una idea central de su trabajo es que esta saga conecta con nosotros porque trae a la actualidad la figura del héroe tal como la definió Joseph Campbell en El héroe de las mil caras. Esto es importante porque el ser humano "construye el mito [...] pero también lo vive" $(197)^{1}$. Dichos filmes son universales porque presentan:
arquetipos, nociones comprensibles por todos los seres humanos: el héroe, el maestro, la lucha del bien y el mal, el camino de perfección, el viaje, el regreso de un ser cuya iden- tidad está reforzada por una aventura con significado amplio y ambicioso (225).

En este sentido, estas obras expresan una lucha universal que las convierte en el sueño colectivo del que habló Campbell. Vamos a sintetizar algunas de las mayores aportaciones de Eduardo Martínez en relación con la última trilogía, pero esto nos llevará también a pensar sobre toda la saga.

Después de que en el episodio VI los jedi acabaran con el emperador, esta trilogía presenta a la Primera Orden, una nueva organización que se ha hecho con el poder frente a unos rebeldes que parece que han retrocedido otra vez a la clandestinidad. Esto representa un paralelismo con el pasado de la saga y un ejemplo más de la constante lucha entre el bien y el mal que desarrolla La guerra de las galaxias. En los episodios I, II y III el régimen imperante era la república, aunque ya se mostraba una transición hacia el imperio, lo cual

1 Todas las citas pertenecientes a La guerra de las galaxias. El mito renovado corresponden a Martínez Rico, 2017, por lo cual sólo se anota el número de página. 
culmina en el episodio III. En los episodios IV, V y VI —es decir, los que realizó Lucas como director o productor en las décadas de los setenta y ochenta-, se produce la lucha entre el imperio y los rebeldes (lo que queda de la antigua república), hasta destruir el imperio (episodio VI, El retorno del jedi). En esta nueva trilogía se nos cuenta una parte más del mismo proceso, algo cíclico. En un primer momento, la resistencia reacciona frente a la Primera Orden - antiguo Impero Galáctico-. En el fondo, los sistemas políticos se muestran como manifestaciones de esa pugna entre los sith y los jedi, entre el mal y el bien, unos luchando contra otros en pos de su propio equilibrio. Heráclito afirmaba, y lo cita Campbell en El héroe de las mil caras, que de la discordia nace el equilibrio.

Señala Eduardo Martínez que El despertar de la fuerza no tiene un argumento muy original porque su objetivo está puesto en enlazar con las anteriores películas y con la audiencia para "recuperar la magia de la trilogía antigua" (271). Un ejemplo de esa vuelta a los orígenes lo podemos observar en Han Solo, uno de los personajes más queridos por el público. En la segunda trilogía, pasa de ser un cínico contrabandista aparentemente centrado en el lucro personal a convertirse en uno de los héroes de la Alianza Rebelde. Se hace amigo de Luke y Leia y se involucra en el ataque a la Estrella de la Muerte para apoyarlos. Lleva a cabo el camino del héroe planteado por Campbell hasta que triunfa en lo bélico, en lo político y en lo amoroso en El retorno del jedi. Sin embargo, esa armonía se rompe en El despertar de la fuerza, donde vuelve a ser un contrabandista al margen de la resistencia cuya única compañía es Chewbacca. Es uno de los casos más significativos que muestra cómo las fuerzas del bien ahora están disgregadas y el Nuevo Orden impera, aunque queda abierta la posibilidad de un cambio.

En Los últimos jedi esa esperanza es muy escasa, especialmente cuando Rey llega al planeta oculto Ahch-To y, en lugar de encontrar a un fuerte y luchador Luke Skywalker, se topa con un hombre destrozado que no quiere pelear. Luke está muy cansado, también indignado, extremadamente enfadado. Siente que ha fracasado porque adiestró a su propio sobrino, Ben Solo (o Kylo Ren), en los senderos de la fuerza y éste se pasó al lado oscuro. Además, Ben Solo debía ser la gran esperanza para la paz, para la república y la armonía de la fuerza, aparte del futuro de los jedi. Luke decide regresar al primer templo jedi. Es muy propio de los miembros de esta orden el retirarse del mundo y dedicarse a la meditación en sitios muy apartados: Yoda en Dagobah, Obi-Wan en Tatooine. En palabras de Eduardo Martínez, el papel de Luke en los episodios VII y VIII recuerda al de Obi-Wan en el episodio IV. "Eres nuestra única esperanza”, le decía Leia a Obi-Wan en su mensaje transmitido 
por R2. En esta película, la esperanza recae en que Luke adiestre a Rey, quien tiene una gran capacidad, pero se sabe muy poco sobre quién es y qué puede llegar a hacer. En cualquier caso, como anticipó Eduardo Martínez, el desarrollo de la acción de los jedi (Anakin, Luke, Rey), acaba influyendo decisivamente en la lucha política entre la república y el imperio y entre las fuerzas dirigidas por Palpatine y la república.

La desconfianza de Luke hacia Ben Solo recuerda a la de ObiWan Kenobi con respecto de Anakin Skywalker. En ambos casos, los maestros ven a un joven poderoso, pero cuyas pasiones pueden resultar peligrosas. Obi-Wan estaba muy orgulloso de la trayectoria de su padawan, aunque era muy consciente de su difícil carácter. Luke se siente fracasado con su pupilo Ben Solo, como Obi-Wan con Anakin - “Tú eras el elegido", le grita en medio de la lava en la lucha final del episodio III-. El conflicto vuelve a ser el del bien y el mal, la relación entre maestro y discípulo, y la rabia, por decirlo así, que siente el primero al ver cómo su aprendiz lo decepciona, con todo lo que esto implica, porque estos personajes mueven a muchos otros, incluso, como sabemos, a sistemas políticos o militares: el imperio, la república, la Nueva Orden...

Finalmente, El ascenso de Skywalker responde muchas de las incógnitas que habían sembrado las anteriores películas. Como suele ocurrir con otras cintas que despiertan enormes expectativas, ha cosechado muchas críticas positivas, pero también negativas. Diversos estudiosos han señalados aspectos argumentales poco coherentes o que parecen algo forzados en el conjunto de la trama de La guerra de las galaxias. Sin embargo, una cosa que hace ver Eduardo Martínez es que el valor de estos filmes reside en su capacidad para llevar el mito a un sueño colectivo, tal como señaló Joseph Campbell, sin desdeñar los aspectos técnicos, pues es un grandísimo espectáculo que se disfruta mucho más en pantalla grande, donde brillan maravillosamente todos sus efectos visuales y sonoros. Es decir, esta película hay que verla desde su sentido mítico que explica lo inexplicable. Se trata de un sueño que expresa nuestros deseos y temores, los cuales llevan al enfrentamiento de las grandes fuerzas que están en el ser humano (149).

Uno de los aspectos más esperados de la última entrega era conocer mejor a Kylo Ren y a Rey. Señala Eduardo Martínez que quien ha visto toda la saga y ha hecho un esfuerzo por comprenderla percibe el esfuerzo de los realizadores porque todo encaje en esta trilogía, porque lo nuevo se realice según la lógica de lo ya dado. Y aquí entra también la evolución de estos personajes. En los casos de Kylo Ren y Rey hay mucho de Anakin y Darth Vader, pero también de 
Luke Skywalker. Lucas decía que La guerra de las galaxias era una saga familiar. Esto se entronca, o complementa, con la acción del bien, del mal y de la fuerza en los personajes, aparte, por supuesto, de los movimientos históricos, bélicos y políticos en los que están inmersos, el paso de la república al imperio, la destrucción de este último y su resurgimiento en la Nueva Orden y en la Última Orden en el episodio IX. Eduardo Martínez afirma en su libro que la política va en paralelo con la acción de los personajes, como también se pudo ver en relación con Anakin Skywalker y Padmé Amidala (119120). El vínculo entre Rey y Kylo Ren es un gran diálogo que refleja toda la trilogía en cuanto a las palabras, las acciones y los recuerdos de estos personajes. Los dos se están buscando a sí mismos y al papel que tienen en una historia en la que cada vez son más importantes. En esa búsqueda de sus orígenes y su futuro, la interacción que tienen entre sí es capital. En ambos laten conflictos, dudas, avances y retrocesos; esto ocurre por separado pero también en esa comunicación maravillosa que se da entre ellos. Esta relación tiene referentes anteriores en la saga, porque todo en esta película, y en general en la nueva trilogía, remite a lo anterior.

En conjunto, en la última trilogía encontramos una lucha épica que parece siempre perdida. En las anteriores entregas los rebeldes también luchaban contra un enemigo mucho mayor. El dominio del terror lo controlaba todo. Así parece suceder con la Primera Orden y después con la Orden Final. Tal como afirma Poe Dameron, la resistencia tiene pocos efectivos: "somos la chispa que encenderá el fuego que acabará con la Primera Orden”. No hay ejército que se pueda oponer al imperio, pero sí muchos individuos dispuestos a luchar por la libertad.

Para concluir, se puede decir que La guerra de las galaxias significa para la cultura algo nuevo, muy original, que surge de lo antiguo. Lucas realizó una especie de labor arqueológica, investigando los mitos del hombre, pero también trabajó géneros como la ciencia ficción, apoyándose en su pasión infantil por los seriales televisivos de los space operas. No podemos olvidar que al principio quiso hacer una versión de Flash Gordon, pero como no podía disponer de los derechos acabó haciendo algo distinto. La guerra de las galaxias es un gran fenómeno cultural, no sólo cinematográfico. Siguen la saga millones de personas en todo el mundo. El gran mitólogo Joseph Campbell decía que si uno era capaz de traer algo desconocido u olvidado al mundo de hoy se transformaría en un gran héroe de la cultura. En este sentido, Eduardo Martínez defiende que George Lucas se ha convertido en eso, trayéndonos algo bastante abandonado, la mitología, que no deja de ser paradójica y radicalmente 
nuevo, envolviéndolo en modernos ropajes y vehículos —la ciencia ficción y el cine - para que lo asimilemos y disfrutemos. Desde el punto de vista cultural, La guerra de las galaxias encierra un gran legado del hombre para el hombre. Gracias a esta saga podemos conocer mejor al ser humano, lo que fuimos, lo que somos, y seguramente lo que seremos, porque sus contenidos son atemporales e imperecederos.

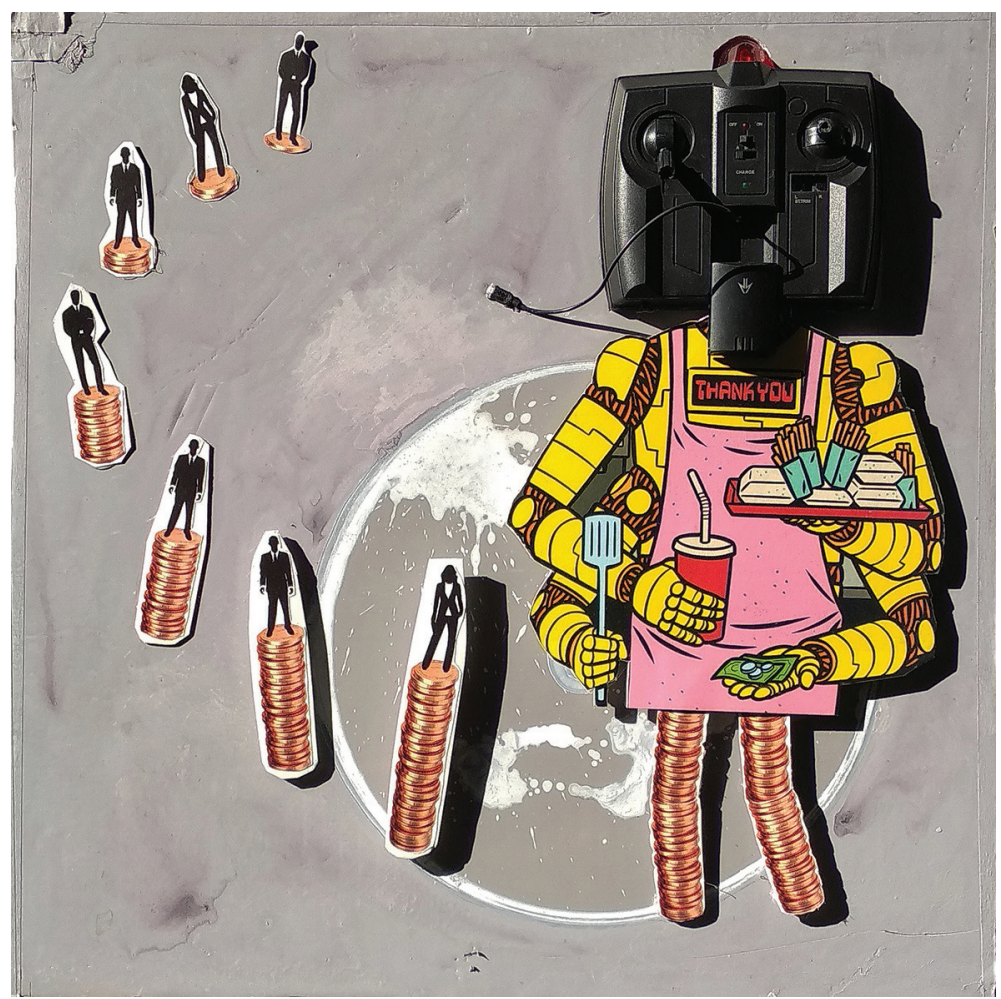

El máquina. Las máquinas que cotizarán por nosotros (2019) Cartón pluma, papel y anilina: Antonio García López

Prohibida su reproducción en obras derivadas.

Santiago Sevilla Vallejo. Licenciado en Teoría de la Literatura y Literatura Comparada, máster en Estudios Literarios y doctor en Estudios Literarios por la Universidad Complutense de Madrid (UCM), España. Miembro del comité directivo de la Asociación de Estudios Manuel Vázquez Montalbán, miembro del consejo de redacción de Cuadernos de Estudios Manuel Vázquez Montalbán y director de la revista Cálamo FASPE. Profesor de la Universidad de Alcalá (UAH), España. Entre sus líneas de investigación se encuentran: identidad para fines educativos, literarios y psicológicos; el discurso como herramienta de construcción del conocimiento; las competencias comunicativas y artísticas; y la narrativa contemporánea. 